\title{
Mortality and Pathology Associated with Highly Pathogenic Avian Influenza H5N1 Outbreaks in Commercial Poultry Production Systems in Nigeria
}

\author{
Olatunde Babatunde Akanbi ${ }^{1,2}$ and Victor Olusegun Taiwo ${ }^{2}$ \\ ${ }^{1}$ Central Diagnostic Laboratory, National Veterinary Research Institute, PMB 1, Vom 930001, Plateau State, Nigeria \\ ${ }^{2}$ Department of Veterinary Pathology, Faculty of Veterinary Medicine, University of Ibadan, Ibadan 200284, Oyo State, Nigeria \\ Correspondence should be addressed to Olatunde Babatunde Akanbi; olatunde.akanbi@nvri.gov.ng
}

Received 3 May 2014; Revised 1 July 2014; Accepted 29 July 2014; Published 22 October 2014

Academic Editor: Tom Aire

Copyright (C) 2014 O. B. Akanbi and V. O. Taiwo. This is an open access article distributed under the Creative Commons Attribution License, which permits unrestricted use, distribution, and reproduction in any medium, provided the original work is properly cited.

Commercial layer-type, pullet, cockerel, and broiler chicken flocks infected with highly pathogenic avian influenza (HPAI) H5N1 in Nigeria between 2006 and 2008 were investigated for morbidity, mortality, and pathology. Of the one hundred and fifty-three (153) farms confirmed with HPAI infection, one hundred and twenty-seven (127) were layer-type farms, nine (9) were pullet and broiler farms each, and eight (8) were cockerel rearing farms. This study revealed the morbidity and mortality of a total of 939,620 commercial layer chickens, 16,421 pullets, 3,109 cockerels, and 6,433 broilers. Mortality rates were $11.11 \%$ in commercial layers, $26.84 \%$ in pullets, $45.51 \%$ in cockerels, and $73.92 \%$ in broilers in a total of eighteen (18) states and the Federal Capital Territory, Abuja. A total of 316 carcasses were examined of which 248 were commercial layer, 25 were pullet, 14 were cockerel, and 29 were broiler. Main clinical and pathologic findings were observed in the nervous, circulatory, respiratory, integumentary, musculoskeletal, hemopoietic, gastrointestinal, and reproductive systems and, occasionally, lesions were generally nonspecific and multisystemic. Lesions occurred more frequently, severely, and in most of the carcasses examined, irrespective of chicken type.

\section{Introduction}

The index HPAI-H5N1 was confirmed in Nigeria at a commercial poultry farm in Kaduna state, and, by the end of the initial outbreak, over 46,000 poultry $[1,2]$ had been destroyed. This outbreak brought the Asian strain of highly pathogenic avian influenza (HPAI) $\mathrm{H} 5 \mathrm{~N} 1$ into Africa for the first time in the beginning of January, 2006 [3-7] in Nigeria. Nigeria lost 945,862 birds of various species at midJanuary [8], 2007. Since its emergence in Africa in 2006, avian influenza viruses of the $\mathrm{H} 5 \mathrm{~N} 1$ subtype have spread rapidly to poultry farms in several African countries. It has caused deaths of millions of birds in Africa [9], as is the case in other affected parts of the world. Highly pathogenic avian influenza (HPAI) is caused by AIVs that are extremely virulent [10], causing up to $100 \%$ mortality in domestic chickens. The H5N1 highly pathogenic avian influenza (HPAI) virus has been a great concern not only for the poultry industry but also for human health [11] since 1997. Following the index HPAI-H5N1 in Nigeria, several efforts have been directed to increased surveillance and diagnosis of the disease. This has led to increased diagnostic capacity, reporting, and research into the diverse genotype of $\mathrm{H} 5 \mathrm{~N} 1$ isolates from Nigeria. The commercial poultry production system in Nigeria as categorized by the FAO [12], which stems from the two major systems: rural poultry production and commercial poultry production, was affected by the HPAI outbreaks. Also, several attempts were made to determine the losses in terms of the number of poultry, monetary, and social values as a result of the disease burden [8] in Nigeria. These attempts have been at some point in the course of the disease [8] or aimed at a particular region of the country [13] due to some identified constraints. Also no overall, detailed clinical and pathological record has been given on a case by case basis for all the outbreaks as seen from different states and regions of the countries which could highlight factors involved in 
the spread of the disease. In early 2006, Joannis et al. 2006 [4], in their letter to the Veterinary Record, mentioned a few lesions seen in the index case. In addition, Adene et al. 2006 [2] described the clinicopathological and husbandry features associated with the maiden diagnosis of AI in Nigeria. Other reports were limited to cases seen in 2006 [14, 15] only. Akanbi et al. 2007 [5] had earlier reported lesions which depict circulatory disturbances, respiratory, intestinal, and reproductive system pathology in selected cases. This study aimed at achieving the determination of the losses on a state by state basis and the total losses recorded during the entire course of the disease in Nigeria and also aimed at highlighting the morbidity, mortality, and pathology in the commercial poultry production systems as practiced in Nigeria.

\section{Materials and Methods}

Data. All the data including state, location, farm flock size, and morbidity and mortality records used in this study were supplied directly by clients who reported and submitted carcasses of layers, pullet, cockerels, and broilers for postmortem examination and avian influenza diagnosis at the National Veterinary Research Institute (NVRI), Central Diagnostic Laboratory, Vom.

Carcasses. A total of three hundred and sixteen (316) carcasses from one hundred and fifty-three (153) farms from eighteen (18) states and the Federal Capital Territory, Abuja, were examined. These carcasses were submitted directly by clients for postmortem examination and avian influenza diagnosis and were selected based on laboratory confirmation of HPAI $\mathrm{H} 5 \mathrm{~N} 1$ virus infection at the NVRI laboratory.

Pathology. Carcasses of the commercial birds that died after natural infection with HPAI were submitted for pathological examination. Following postmortem examination of the carcasses, sections of liver, heart, spleen, kidney, lung, trachea, proventriculus, gizzard, duodenum, ileum, cecum, and brain were removed and fixed in $10 \%$ buffered formalin. All tissue samples were then embedded in paraffin, sectioned at $5 \mu \mathrm{m}$, mounted on clean glass slides, and stained with hematoxylin and eosin (H\&E) stains for histopathologic examination using low and high powered field of Carl Zeiss or Nikon binocular microscope.

Virus Isolation. For virus isolation, samples of liver, heart, spleen, kidney, lung, trachea, duodenum, and caecum were removed and submitted for virological investigation, where the homogenates of the trachea, lung, liver, spleen, and kidney were inoculated via the allantoic cavity into 9-11-dayold embryonating chicken eggs [16] obtained from specific antibody negative chickens.

\section{Results}

3.1. Data Set Distribution. During the period under review (2006-2008), a total of eighteen (18) states (Adamawa, Bauchi, Bornu, Jigawa, Kaduna, Kano, Katsina, Sokoto, Plateau,
Nasarawa, Kwara, Lagos, Ogun, Oyo, Rivers, Edo, Anambra, and Enugu) and the Federal Capital Territory, Abuja, had confirmed HPAI H5N1 outbreaks in commercial layer, pullet, cockerel, and broiler (Table 1). A total of one hundred and fourteen thousand, nine hundred and twenty-nine $(114,929)$ commercial chickens died from a total flock size of nine hundred and sixty-five thousand, five hundred and eightythree $(965,583)$ before the rest of the flocks were stamped out. The north-western region recorded the highest number of mortalities in commercially raised chickens as a result of natural infection with HPAI in Nigeria. The figure $(69,741)$ represents $60.68 \%$ of the total number $(114,929)$ of commercially raised chickens that died as a result of HPAI (Table 1). While the total number of chicken losses as a result of HPAI death and stamping out in this region $(438,386)$ was second to the south-western region where commercial bird losses totaled 445,320 and the number that died as a result of HPAI when the reporting was done was 26,878 , being $23.38 \%$ of the total number of commercial chickens that died as a result of HPAI.

3.2. Mortality. Mortality rates were the highest in broilers flocks $(73.92 \%)$ and the least in layers flocks (11.11\%). The mortality rate was $45.51 \%$ in cockerels and was $26.84 \%$ in pullet. A breakdown of the figures, which showed layer flocks, has been the most affected commercial chicken type with a total bird loss of 939,620, representing $97.31 \%$ of the commercially raised chickens. Of the 939,620 layer population affected in 127 farms, 104,351 layers, representing $90.79 \%$ of 114,929 , died as a result of direct HPAI infection in layer flocks. Eight hundred and fifty thousand, six hundred and fifty-four $(850,654)$ birds, which represent the difference between the flock size and the number of the dead, were stamped out. Broilers were the second most affected commercial chicken type of which 6,433 , representing $0.66 \%$ of the total flock size $(965,583)$ of commercially raised chickens, were affected by HPAI. Of the 6,433 broilers affected, 4,755 broilers, representing $4.14 \%$ of the total number of commercially raised chickens $(114,929)$, died as a result of direct HPAI infection, while the remaining broilers were stamped out. Pullets were the next affected commercial chicken type of which $16,421(11.70 \%)$ were affected and $4408(3.84 \%)$ were reported to be dead. Cockerel was the least affected commercial chicken type of which 3109 (0.32\%) were affected and $1,415(1.23 \%)$ were reported to be dead.

3.3. Clinical Signs and Pathology. Main clinical and pathologic findings were observed in the nervous, circulatory, respiratory, integumentary, musculoskeletal, gastrointestinal, and reproductive systems and occasionally lesions are multisystemic. Signs observed and reported are sudden death, high mortality, weakness, and recumbency. Others ranged from nasal discharges, dyspnea, coughing, sneezing, diarrhea, shank hyperemia and haemorrhage, inability to stand, ataxia, and torticollis. In layers, egg structural abnormalities such as shell-less egg, white-colored eggs, and soft eggs were reported. Lesions observed in the circulatory system included congestion (Figures 1 and 2) and cyanosis of comb and wattle, 
TABLE 1: Commercial poultry losses in HPAI infection in Nigerian states and region.

\begin{tabular}{|c|c|c|c|c|c|}
\hline$S / N$ & Zone & State & Flock size & Number of the dead & Chicken type \\
\hline & \multirow{3}{*}{ Northeast } & Adamawa & 55 & 36 & Cockerel \\
\hline & & Bauchi & 28731 & 4637 & Layer, pullet, broiler \\
\hline & & Bornu & 800 & 207 & Layer, pullet, cockerel \\
\hline & Regional subtotal & & 29586 & 4880 & \\
\hline & \multirow{5}{*}{ Northwest } & Jigawa & 13786 & 3000 & Layer \\
\hline & & Kaduna & 87435 & 51333 & Layer, pullet, broiler, cockerel \\
\hline & & Kano & 234998 & 7930 & Layer, cockerel \\
\hline & & Katsina & 95605 & 6778 & Layer \\
\hline & & Sokoto & 6562 & 700 & Layer \\
\hline & Regional subtotal & & 438386 & 69741 & \\
\hline & \multirow{4}{*}{ North central } & Abuja & 236 & 165 & Layer, broiler \\
\hline & & Plateau & 24210 & 4712 & Layer, pullet, broiler, chick \\
\hline & & Nasarawa & 58 & 56 & Broiler, cockerel, mixed \\
\hline & & Kwara & 6685 & 1485 & Layer \\
\hline & Regional subtotal & & 31189 & 6418 & \\
\hline & \multirow{3}{*}{ Southwest } & Lagos & 291780 & 21632 & Layer, pullet, broiler \\
\hline & & Ogun & 138536 & 642 & Layer, cockerel \\
\hline & & Oyo & 15004 & 4604 & Layer, broiler, cockerel \\
\hline & Regional subtotal & & 445320 & 26878 & \\
\hline & \multirow{2}{*}{ South-south } & Rivers & 1200 & 200 & Layer \\
\hline & & Edo & 6500 & 5109 & Layer, pullet, broiler \\
\hline & Regional subtotal & & 7700 & 5309 & \\
\hline & \multirow{2}{*}{ Southeast } & Anambra & 13352 & 1653 & Layer \\
\hline & & Enugu & 50 & 50 & Broiler \\
\hline & Regional subtotal & & 13402 & 1703 & \\
\hline & National total & & 965583 & 114929 & \\
\hline
\end{tabular}

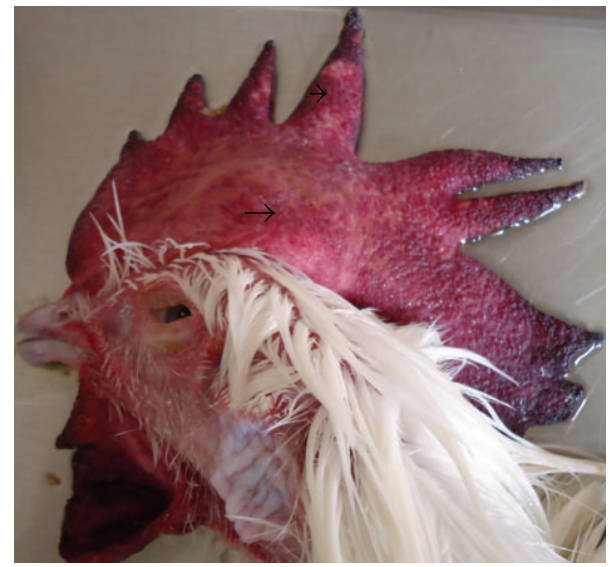

Figure 1: Layer chicken, head showing swollen comb (arrow) and congestion (arrow head).

comb and wattle edema, and facial and subcutaneous edema. Within the respiratory system, there were airsacculitis and pneumonia. There was petechiation to ecchymoses of the proventricular (Figure 3) and intestinal mucosa with resultant enteritis in the gastrointestinal system. Integumentary system lesions are mainly cyanosis, edema, and ecchymotic

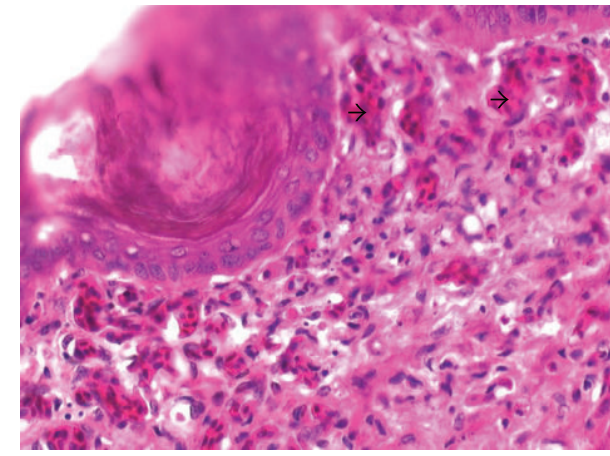

FIGURE 2: Layer chicken, comb showing severe dermal vascular congestion (arrow heads) H\&E, $\times 400$.

hemorrhages while there were inflammatory, degenerative, and necrotic lesions in the musculoskeletal system. In adult birds, mainly layers reproductive lesions were observed and they were mainly ovarian follicular ecchymotic hemorrhages (Figure 4).

Layers. Most of the commercially raised layers (67\%) exhibited lesions of the circulatory system, mainly cyanosis of comb and wattle with occasional facial edema. Only $20 \%$ showed nervous signs and brain lesions of neuronal and 


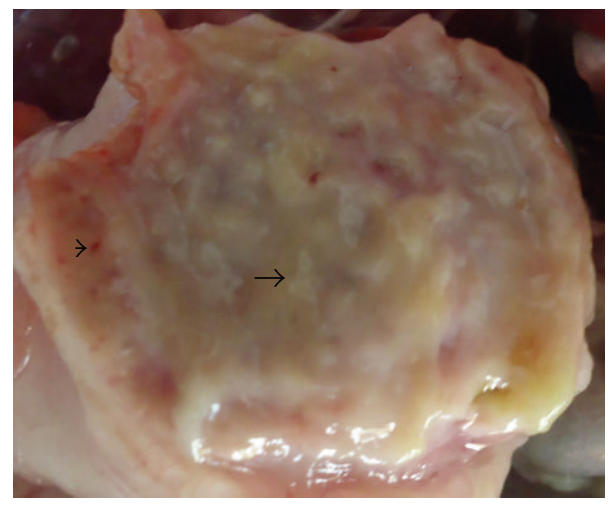

FIGURE 3: Layer chicken, proventriculus showing swollen glands with excess mucous exudates (arrow) and mild multifocal to diffuse petechiae hemorrhages (arrow head).

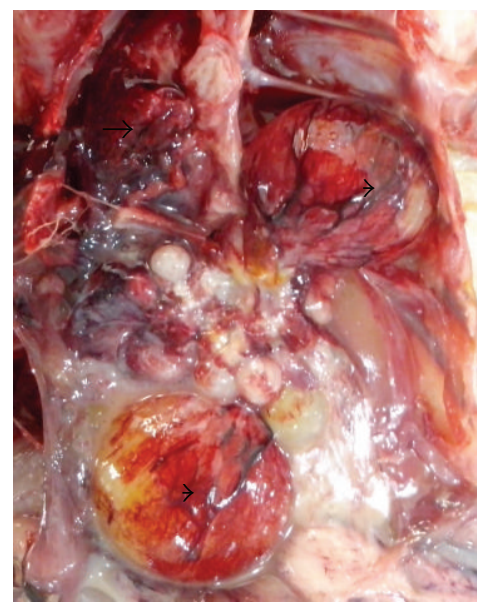

FIGURE 4: Layer chicken, thoracic and abdominal cage, showing congested and consolidated lungs (arrow) and haemorrhagic ovarian follicles (arrow head).

Purkinje cell necrosis of cerebrum and cerebellum, respectively. Respiratory lesion of airsacculitis and pneumonia (Figure 4) with vascular congestion (Figure 5) was evident in $43.5 \%$ with more than half having pneumonia. Of the 70 clinical reports of diarrhea, only 42 had enteritis and 18 were hemorrhagic. Enteric petechiation and ecchymoses were observed in 45 of the carcasses while pancreatic necrosis was occasionally encountered (Figures 6 and 7). Splenic necrosis and loss of lymphoid cells were also seen in the carcasses (Figure 8). A few carcasses (6.4\%) showed integumentary system lesions; these are mainly cyanosis, edema, and ecchymotic hemorrhages. Only $13.7 \%$ had muscular hemorrhages with necrosis, and/or myositis. Reproductive lesions were only observed in these layers, and these were observed in $15.3 \%$ only. These were mainly ovarian follicular ecchymotic hemorrhages and structure abnormality. Fortyone (41) percent of the layers had multisystemic lesions.

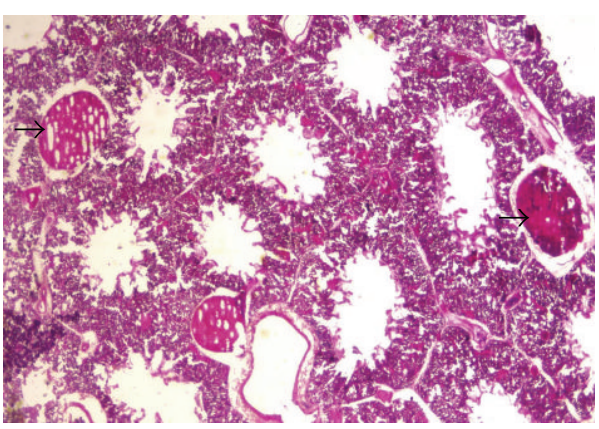

FIGURE 5: Layer chicken, lung showing severe multifocal vascular congestion (arrow), H\&E, $\times 400$.

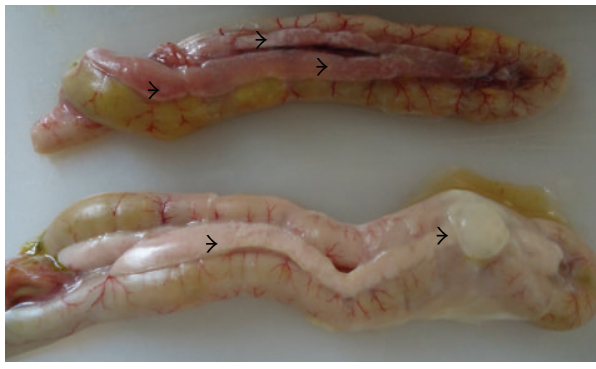

FIGURE 6: Layer chicken, duodenal loop showing multifocal necrosis on the pancreas (arrow heads).

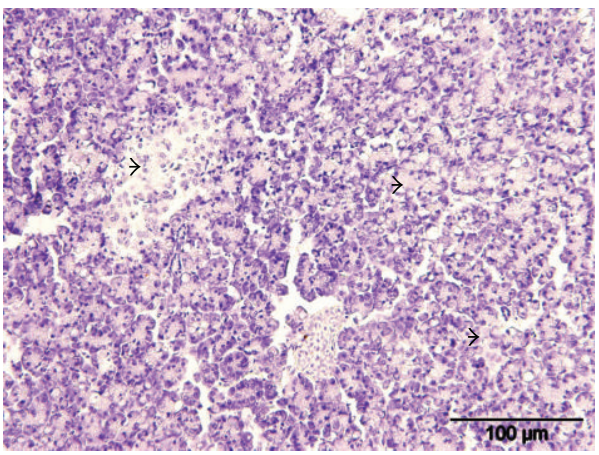

FIGURE 7: Layer chicken, pancreas showing diffuse necrosis of acinar cells of the pancreas (arrow heads) H\&E.

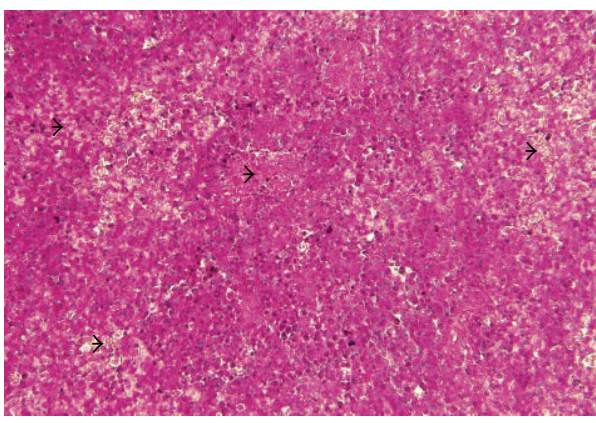

FIGURE 8: Layer chicken, spleen showing severe diffuse lymphoid necrosis and depletion (arrow heads) H\&E, $\times 400$. 


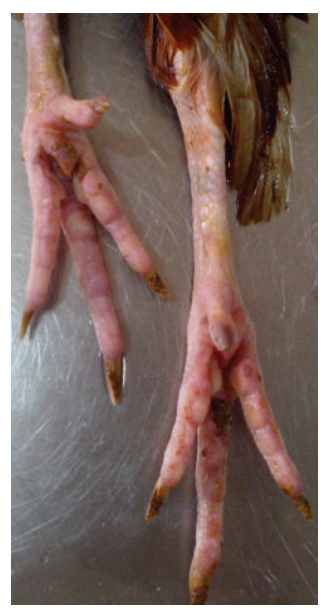

FIGURE 9: Layer chicken, shank showing hyperemia.

Shank hyperemia (Figure 9) and haemorrhage were also frequently seen.

Pullet. Of the twenty-five (25) pullet carcasses examined, $60 \%$ had report of the circulatory system signs, mainly cyanosis of comb and wattle with occasional facial edema. Only $4 \%$ showed nervous lesion in the brain such as neuronal and Purkinje cell necrosis of cerebrum and cerebellum, respectively. Respiratory lesions of nasal exudation, airsacculitis, and pneumonia were evident in $32 \%$. Enteric lesion was observed in 3 (12\%) of the 25 carcasses examined. Twentyeight (28) percent had muscular and shank hemorrhages with necrosis, and/or myositis. Twenty-four (24) percent of the pullets which died suddenly were from flocks with high mortality and also had multisystemic lesions. No lesion was observed in the integumentary and reproductive systems, respectively, in all carcasses examined.

Broiler. Of the twenty-nine (29) broiler carcasses examined, $82.7 \%$ had lesions of the circulatory system, mainly cyanosis of comb and wattle with occasional facial edema. Only 4 (13.7\%) showed brain lesions of neuronal and Purkinje cell necrosis of cerebrum and cerebellum, respectively. Respiratory lesions of airsacculitis and pneumonia were evident in fourteen (48.2\%) carcasses. Enteric lesion was observed in 9 (31\%) of the 29 carcasses examined. Five (17.2\%) carcasses had muscular and hemorrhages with necrosis and/or myositis. Ten $(34.4 \%)$ of the broilers which died suddenly were from flocks with high mortality and had multisystemic lesions. No lesion was observed in the integumentary and reproductive systems, respectively, in all carcasses examined.

Cockerel. Of the fourteen (14) cockerel carcasses examined, $64 \%$ had lesions of the circulatory system, mainly cyanosis of comb and wattle with occasional facial edema. Only 5 (35.7\%) showed nervous lesions of neuronal and Purkinje cell necrosis of cerebrum and cerebellum, respectively. Respiratory lesions of airsacculitis and pneumonia were evident in five (35.7\%) carcasses. Enteric lesion was observed in 6 (42.8\%) of the 14 carcasses examined. Eight (57.1\%) carcasses had muscular and shank hemorrhages with necrosis and/or myositis. Five (35.7\%) of the pullets which died suddenly were from flocks with high mortality and had multisystemic lesions. No lesion was observed in the integumentary and reproductive systems in all carcasses examined.

\section{Discussion}

The north-western region recorded the highest number of mortalities in commercially raised chickens as a result of natural infection with HPAI in Nigeria. This represents $60.68 \%$ $(69,741)$ of the total number of chickens which died as a direct result of HPAI infection. The total number of chickens which died as a direct result of HPAI infection and those that were stamped-out in this region was 438,386 , only second to the total number of chickens which died as a direct result of HPAI infection and those that were stamped out in the south-western region which stood at 445,320. Indeed, southwestern Nigeria, particularly the states surrounding the city of Lagos [17], holds much of Nigeria's poultry industry. It is estimated that over $65 \%$ of Nigeria's commercial poultry are located in the five southern states [17] of Lagos, Ogun, Oyo, Osun, and Ondo. A very high number of poultry deaths and losses were also reported in a north-western regional [13] avian influenza investigation in the north-western region, apart from the fact that it was in this region where the first outbreak of HPAI in Nigeria was reported $[4,18]$ in a farm that had predominantly commercial birds $[2,14]$. Although the total poultry losses were higher in the southwest region, the total number of chickens which died as a direct result of HPAI infection was 26,878 being $23.38 \%$ of the national total number of commercially raised chickens that died as a direct result of HPAI infection, as compared with $60.68 \%(69,741)$ in the northwest. This difference may be as a result of the fact that the farms in the southwest are more organized and densely stocked as compared with those in the northwest which are not well organized and not as densely stocked. The finding of high mortality in the north-western states is consistent with earlier reports $[2,13]$. In the northwestern regional analysis [13] which excluded bird losses in Sokoto state, four hundred and eighty thousand, three hundred and seventy-eight $(480,378)$ birds were reported as being lost as a result of HPAI incursions and stamping out. The deviation of this finding from ours may be as a result of nonseparation between the various sectors of poultry production systems, as it includes backyard flocks and noncommercial and commercial flocks. The northcentral states had a mortality of 6418 (5.58\%) being the total number of commercial chickens that died as a result of HPAI when the reporting was done, while the total number of chicken losses as a result of natural death and stamping out policy in this region was 31,189 . The south-south region lost more birds to direct HPAI infection (5309) as compared to the north-eastern region (4880) but more birds (29586) were destroyed in the northeast than in the south-south where 7,700 birds were destroyed. The southeast lost the least 
number of birds to HPAI (1703) but had a high number of birds' losses to HPAI and stamping out (13402). Under the commercial poultry production sector practiced in Nigeria [17], the commercial layer-type chicken was the most hit by the highly pathogenic avian influenza outbreaks experienced by the Nigerian poultry industry. With a total flock size of 939,620 lost in 127 farms having confirmed outbreaks, the commercial layer-type chicken suffered a major economic loss and devastation. This is attributed to the large number of laying birds in individual flocks as compared to other chicken types under these sectors. This significantly affected the economy not only because a whooping sum of N631 million (US $\$ 5.43$ million) was paid as compensations to farmers [19] but also because laying hens contribute huge resources to the national poultry flock and this emphasizes the importance of commercial layer flocks [20] for Nigeria's economy. It was also observed that the average mortality rate was the least in commercial layers (11.11\%) and the highest in broilers (73.92). This may be as a result of the cage housing of commercial layers which restrict movement and contact between HPAI infected ones and noninfected ones compared with broilers raised in deep litter and which also share water and feed sources. Average mortality rate was higher in cockerels (males $=45.51 \%$ ) than in pullets (females $=26.84 \%$ ). The necropsy finding observed in the 316 carcasses examined of which 248 were commercial layer, 25 were pullet, 14 were cockerel, and 29 were broilers cut across more than one system and occurred more frequently and severely and in most of the carcasses examined irrespective of chicken type. In commercial layers, the systems affected included mainly circulatory, respiratory, and intestinal systems as observed by earlier investigators from the index case of HPAI $[2,4]$ in Nigeria. Only $20 \%$ of the 248 layer carcasses had neurologic signs and lesions contrary to what was observed in the index case where only young stocks had nervous system signs [2]. Also, other investigators reported presence of nervous signs and lesion with no particular reference to age [4] and with reference to adult birds [15]. Eighty-two percent $(82.7 \%)$ of the broilers showed signs and lesions of circulatory disturbances followed by $67 \%$ in layers. More broilers and cockerels showed neurological signs and lesion more than in layers. This work was able to document the total HPAI bird losses in commercially raised chickens in Nigeria on a state by state cases and region by region cases, previously unreported. It also showed that mortality was the highest in broiler and males (cockerels) had more death than females (pullets).

\section{Conclusion}

This study was able to document the losses in HPAI infected commercial chickens in Nigeria and the overall pathological findings of HPAI infection in chickens in Nigeria previously unreported.

\section{Conflict of Interests}

The authors declare that there is no conflict of interests regarding the publication of this paper.

\section{Acknowledgments}

The authors would like to acknowledge the technical assistance of Ben Bako, Rebecca Kaye, Alesa Mada, and Victoria Olabode and the cooperation of the National Veterinary Research Institute, Vom, Nigeria.

\section{References}

[1] "N.V.R.I records," National Veterinary Research Institute, Case database, Vom, Nigeria, 2006.

[2] D. F. Adene, A. M. Wakawa, P. A. Abdu et al., "Clinico-pathological and husbandry features associated with the maiden diagnosis of Avian Influenza in Nigeria," Nigeria Veterinary Journal, vol. 27, no. 1, pp. 32-38, 2006.

[3] M. Enserink, "Avian influenza. H5N1 moves into Africa, European Union, deepening global crisis.," Science., vol. 311, no. 5763, p. 932, 2006.

[4] T. Joannis, L. H. Lombin, P. de Benedictis, G. Cattoli, and I. Capua, "Confirmation of H5N1 avian influenza in Africa," Veterinary Record, vol. 158, no. 9, pp. 309-310, 2006.

[5] B. O. Akanbi, J. P. Teifke, P. S. Ekong, E. T. Ighodalo, A. Ogunsan E, and A. A. Makinde, "The epidemiology, pathology and immunohistochemistry of Nigerian highly pathogenic avian influenza (HPAI) H5N1 virus infection in chickens," in Proceedings of the 44th Annual Congress of the Nigerian Veterinary Medical Association (NVMA) Conference, pp. 162-165, Effurun, Nigeria, October 2007.

[6] M. F. Ducatez, C. M. Olinger, A. A. Owoade et al., "Molecular and antigenic evolution and geographical spread of $\mathrm{H} 5 \mathrm{~N} 1$ highly pathogenic avian influenza viruses in western Africa," Journal of General Virology, vol. 88, no. 8, pp. 2297-2306, 2007.

[7] I. Monne, T. M. Joannis, A. Fusaro et al., "Reassortant avian influenza virus (H5N1) in poultry, Nigeria, 2007," Emerging Infectious Diseases, vol. 14, no. 4, pp. 637-640, 2008.

[8] F. O. Fasina, A. C. Meseko, T. M. Joannis et al., "Control versus no control: Options for avian influenza H5N1 in Nigeria," Zoonoses and Public Health, vol. 54, no. 5, pp. 173-176, 2007.

[9] H. Yoon, C. K. Park, H. M. Nam, and S. H. Wee, "Virus spread pattern within infected chicken farms using regression model: the 2003-2004 HPAI epidemic in the Republic of Korea," Journal of Veterinary Medicine, vol. 52, no. 10, pp. 428-431, 2005.

[10] S. B. Muzaffar, J. Y. Takekawa, D. J. Prosser, S. H. Newman, and X. Xiao, "Rice production systems and avian influenza: interactions between mixed-farming systems, poultry and wild birds," Waterbirds, vol. 33, no. 1, pp. 219-230, 2010.

[11] K. Subbarao, A. Klimov, J. Katz et al., "Characterization of an avian influenza A (H5N1) virus isolated from a child with a fatal respiratory illness," Science, vol. 279, no. 5349, pp. 393-396, 1998.

[12] D. F. Adene and A. E. Oguntade, The Structure and Importance of the Commercial and Village based Poultry Industry in Nigeria, Food and Agricultural Organization, Rome, Italy, 2006.

[13] L. Saidu, A. M. Wakawa, P. A. Abdu et al., "Impact of avian influenza in some states of Nigeria," International Journal of Poultry Science, vol. 7, no. 9, pp. 913-916, 2008.

[14] P. R. Kumbish, T. M. Joannis, A. R. Jambalang et al., "Clinicopathological features of highly pathogenic Avian Influenza (HP AI-H5N1) outbreaks in commercial chickens in Nigeria," Vom Journal of Veterinary Science, pp. 13-22, 2006.

[15] P. de Benedictis, T. M. Joannis, L. H. Lombin et al., "Field and laboratory findings of the first incursion of the Asian 
H5N1 highly pathogenic avian influenza virus in Africa," Avian Pathology, vol. 36, no. 2, pp. 115-117, 2007.

[16] N.V.R.I Records, National Veterinary Research Institute, Vom , Nigeria. Case database, 2006-2008.

[17] Food and Agricultural Organization, "FAO Poultry sector country review-Nigeria," Food and Agriculture Organization of the United Nations, Geneva, Switzerland, 2008.

[18] [NADIS] National Animal Disease Information and Surveillance Info, Special avian flu edition, National Animal Disease Information and Surveillance (NADIS), 10th edition, 2006.

[19] A. Durosinlorun, J. U. Umoh, P. A. Abdu, and I. Ajogi, "Serologic evidence of infection with $\mathrm{H} 5$ subtype influenza virus in apparently healthy local chickens in Kaduna State, Nigeria," Avian Diseases, vol. 54, no. 1, pp. 365-368, 2010.

[20] F. O. Fasina, M. M. Sirdar, and S. P. R. Bisschop, “The financial cost implications of the highly pathogenic notifiable avian influenza H5N1 in Nigeria," Onderstepoort Journal of Veterinary Research, vol. 75, no. 1, pp. 39-46, 2008. 

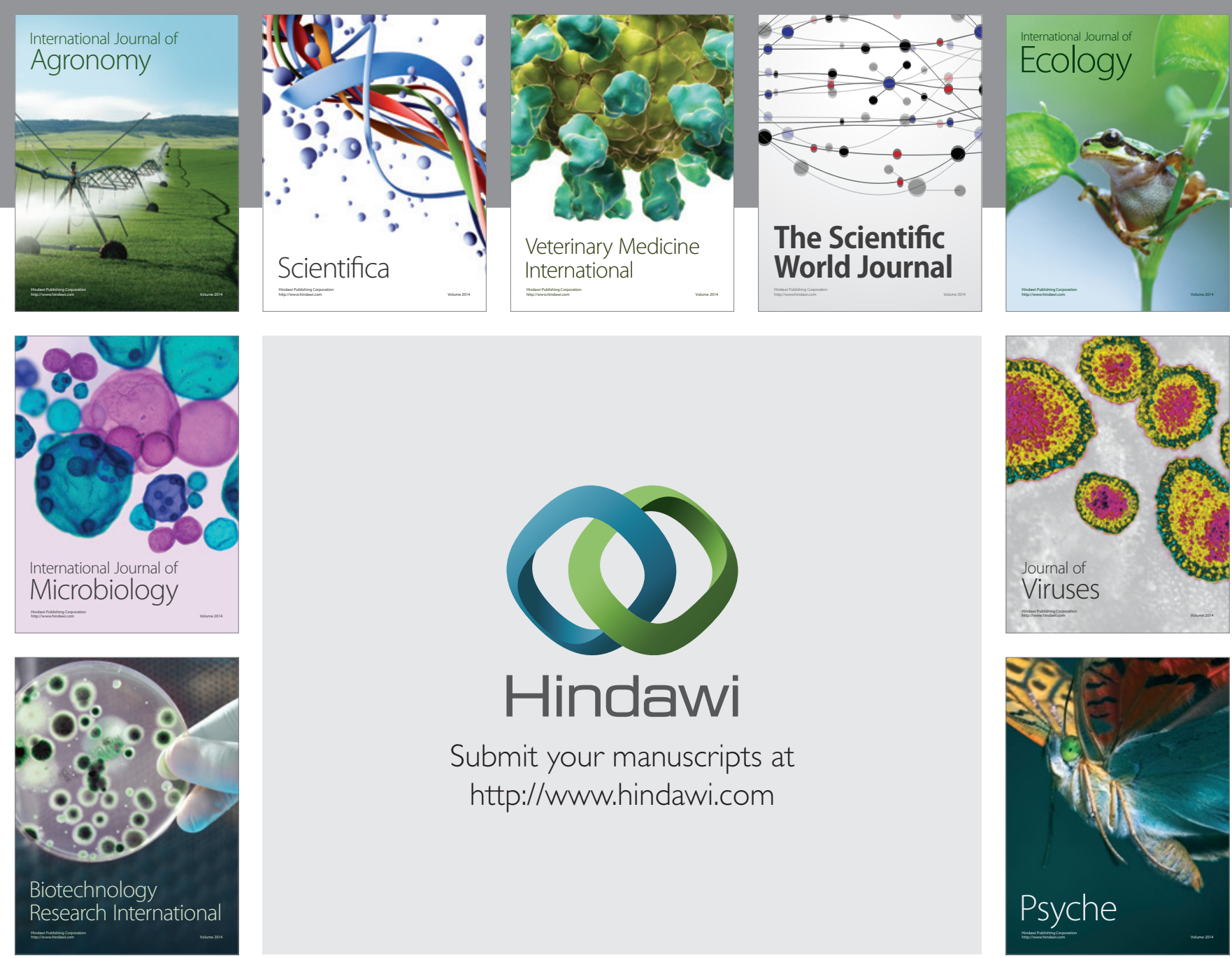

Submit your manuscripts at http://www.hindawi.com
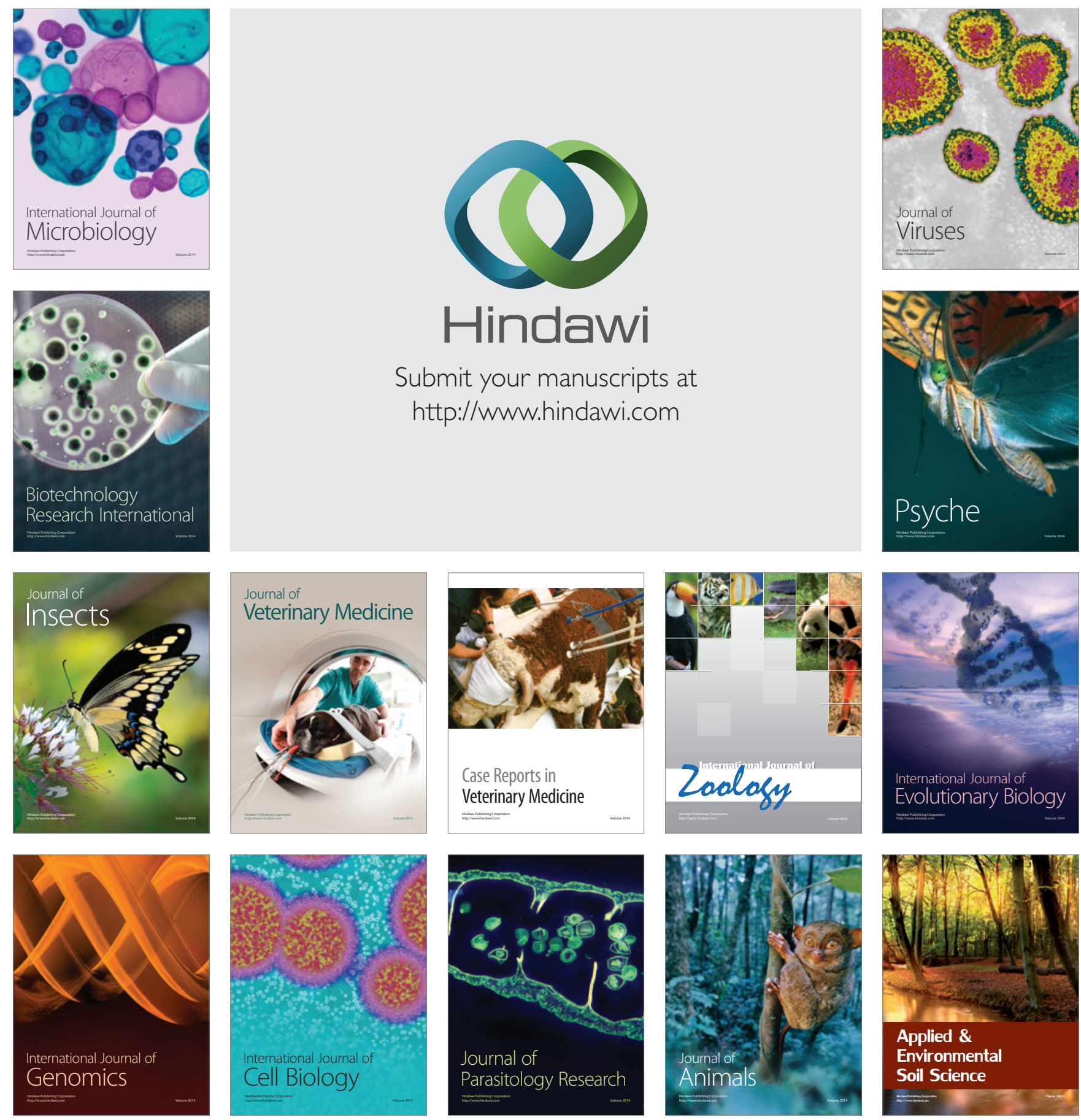